\title{
A rare cause of clitoromegaly: Epidermoid cyst
}

\author{
Selman Karaci ${ }^{1}$, Deniz Kulaksiz ${ }^{2}$, Cagri Akin Sekerci ${ }^{3}$ \\ ${ }^{1}$ Trabzon Kanuni Research and Training Hospital, Plastic \& Reconstructive Surgery, Trabzon, Turkey; \\ ${ }^{2}$ Trabzon Kanuni Research and Training Hospital, Gynecology \& Obstetrics, Trabzon, Turkey; \\ ${ }^{3}$ Trabzon Kanuni Research and Training Hospital, Pediatric Urology, Trabzon, Turkey.
}

\begin{abstract}
Summary Clitoromegaly due to non-hormonal causes is rare. In this case, we aimed to present an epidermal cyst that caused clitoromegaly after traditional female circumcision. A 22-year-old African female was referred to our clinic with enlarged clitoris. There is a mobile, soft, nonfluctuant mass with a size of $6 \mathrm{~cm}$ originating from the clitoral region at physical examination. Under spinal anesthesia the clitoral mass was excised totally and labioplasty was performed. Histopathologic examination was reported as epidermal cyst. Epidermal cyst should be considered after hormonal reasons are excluded in patients with clitoromegaly who have a history of trauma.
\end{abstract}

KEY WORDS: Clitoromegaly; Epidermoid cyst; Female circumcision.

Submitted 1 Februart 2019; Accepted 1 April 2019

\section{INTRODUCTION}

Clitoromegaly often occurs with an increase in endogenous androgen release or by exogenous androgens in women. Non-hormonal causes of clitoral hypertrophy is rare and usually present with benign neoplasms. Fibroma, leiomyoma, angiokeratoma, pseudolymphoma, hemangioma, hemangiopericytoma, granular cell tumor and neurofibroma were reported as bening neoplasm causing clitoromegaly; carcinoma, endodermal sinus tumor, sarcoma, rhabdomyosarcoma, schwannoma, epithelioid hemangioendothelioma and lymphoma as malignant clitoral tumors (1). In this presentation, an asymptomatic clitoral mass due to epidermal cyst developed following female circumcision was reported.

\section{Case report}

A 22-year-old African female was referred to our clinic with enlarged clitoris. The enlargement had been present since early adolescence period. She had a story of traditional female circumcision in early childhood. She had no systemic disease, hirsutism and obesity. She menses regularly every 28 days and secondary sex characteristics were normal. There was a mobile, soft, non-fluctuant mass with a size of $6 \mathrm{~cm}$ originating from the clitoral region in physical examination. Luteinizing hormone, follicle stimulating hormone, serum prolactin, serum cortisol and 17-hydroxyprogesterone were all found within the normal range. Bilateral ovaries and uterus were normal by pelvic ultrasonography. No structure for any male genital organ was observed. For this reason, disorders of sex development were excluded. It was reported as a massive cystic structure with no perfusion on pelvic magnetic resonance imaging. Under spinal anesthesia the clitoral mass was excised totally and labiaplasty was performed. During surgery, glans and neurovascular bundle of the clitoris were not observed. It can be associated with previous female circumcision. There was no complication at the postoperative period. Histopathologic examination was reported as a $5 \times 3 \times$ $2.5 \mathrm{~cm}$ epidermal cyst filled with keratinous material.

\section{Discussion}

Clitoral hypertrophy may be congenital or acquired. Congenital forms are usually observed at birth and develop due to hormonal disorders. Acquired forms can be divided into two forms, hormonal or non-hormonal. Hormonal causes include hypertestosteronism, polycystic ovarian syndrome, virilizing tumors of the ovary or adrenal gland, and exogenous androgen exposure (2). Non hormonal causes are more and are associated with neoplasms.

Epidermoid cyst is one of the rare causes of non-hormonal acquired clitoromegaly. The epidermoid cyst may be intradermal or subcutaneously localized and surrounded by the epidermis wall. Epidermoid cyst is formed by keratinized squamous epithelium invagination into the dermis or subcutaneous tissue spontaneously or following trauma and filled with lamine keratin (3). Epidermal cysts often occupy the vulva or labia major. Clitoral epidermoid cyst can often be observed in African girls or women following trauma caused by genital mutilation (1). Spontaneous development without trauma is rare (2). Anderson-Mueller et al. presented a 17 year-old African-American girl with a painful clitoral mass. Patient had no female circumcision or any genital trauma. After the endocrinological causes were excluded, the neurovascular bundle of clitoris was preserved and the mass was excised. Pathology evaluation reported a benign squamous mucosa with submucosal edema, chronic inflammation, fibrosis, and mild vascular congestion (1). In our case, there was no trauma story and only traditional female circumcision for genital mutilia-

\footnotetext{
No conflict of interest declared.
} 
Figure 1.

Before and after surgery.
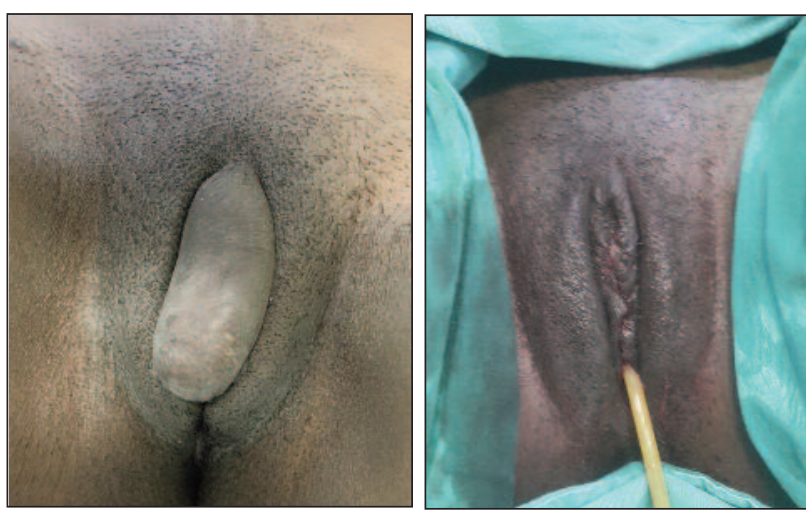

tion. Glandular structure and neurovascular bundle were not observed during surgery, while the corporal bodies were seen as a stump.

Al-Ojaimi et al. reported a 19-year-old female with a giant epidermoid cyst measuring $8 \times 6 \mathrm{~cm}$ (4). In this case, redundant skin was excised after cyst removal. In cases with very large cysts, labiaplasty following excision may be required and we performed it in our case.

Clitoral enlargement during adolescence period is a very rare condition. Endocrinological evaluation should be done after carefully physical examination of internal and external genital system. If necessary, adrenal gland imaging should be included. If non-hormonal causes are diagnosed after this evaluation, biopsy and/or complete resection may be performed (1).

\section{Conclusions}

When clitoral hypertrophy is encountered, endocrinological causes should be ruled out in the first step. Subsequent malignant or benign clitoral lesions should

\section{Figure 2.}

Excised epidermoid cyst and its contents.
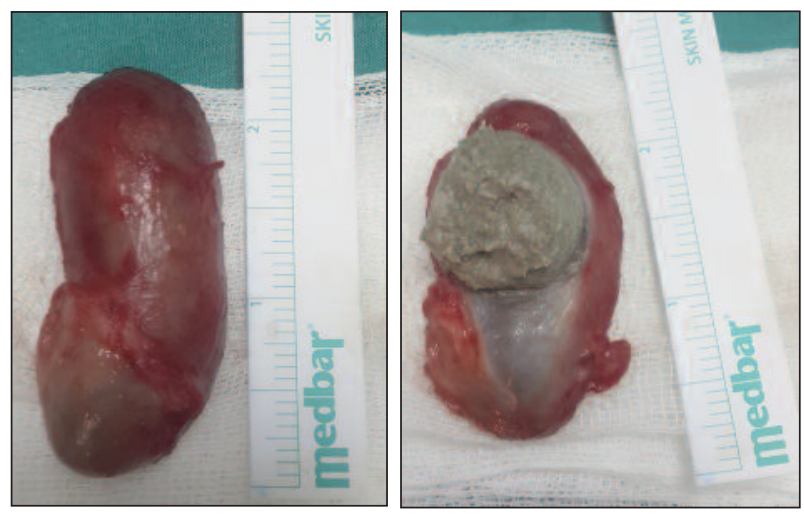

be considered. Imaging methods can be applied in suspicious situations. During the surgical excision, the clitoris (vascularization and innervation) should be protected as much as possible.

\section{REFERENCES}

1. Schmidt A, Lang U, Kiess W. Epidermal cyst of the clitoris: a rare cause of clitoromrgaly. Eur J Obstet Gynecol Reprod Biol. 1999; $87: 163-5$.

2. Anderson-Mueller BE, Laudenschlager MD, Hansen KA. Epidermoid cyst of the clitoris: an unusual cause of clitoromegaly in a patient without history of previous female circumcision. J Pediatr Adolesc Gynecol. 2009; 22:e130-2.

3. Lee HS, Joo KB, Song HT, et al. Relationship between sonographic and pathologic findings in epidermal inclusion cysts. J Clin Ultrasound. 2001; 29:374-83.

4. Al-Ojaimi EH, Abdulla MM. Giant epidermoid inclusion cyst of the clitoris mimicking clitoromegaly. J Low Genit Tract Dis. 2013; 17:58-60.

\section{Correspondence}

Selman Karaci, MD

selmankaraci@gmail.com

Trabzon Kanuni Research and Training Hospital, Plastic \& Reconstructive Surgery, Trabzon (Turkey)

Deniz Kulaksiz, MD

drdenizkulaksiz@hotmail.com

Trabzon Kanuni Research and Training Hospital, Gynecology \& Obstetrics, Trabzon (Turkey)

Cagri Akin Sekerci, MD, FEBU (Corresponding Author)

cagri_sekerci@hotmail.com

Trabzon Kanuni Research and Training Hospital, Pediatric Urology,

Trabzon (Turkey) 